\title{
Endoscopic radiofrequency ablation for malignant biliary strictures
}

\author{
FEI WANG, QUANPENG LI, XIUHUA ZHANG, GUOBING JIANG, XIANXIU GE, \\ HONG YU, JUNJIE NIE, GUOZHONG JI and LIN MIAO \\ Medical Center for Digestive Diseases, The Second Affiliated Hospital of Nanjing Medical University, \\ Nanjing, Jiangsu 210011, P.R. China
}

Received February 2, 2015; Accepted March 14, 2016

DOI: $10.3892 /$ etm.2016.3235

\begin{abstract}
Endoscopic radiofrequency ablation (RFA) is a novel palliation therapy for malignant biliary stricture; however, its feasibility and safety has not yet been clearly defined. The aim of the present study was to evaluate the feasibility and safety of endoscopic RFA for the treatment of malignant biliary strictures. A total of 12 patients treated by endoscopic RFA between December 2011 and October 2013 were retrospectively analyzed. Adverse events within 30 days post-intervention, stricture diameters prior to and following RFA, stent patency and survival time were investigated. A total of 12 patients underwent 20 RFA procedures as a treatment for malignant biliary strictures. Two patients required repeated elective RFA (4 and 6 times, respectively). All 20 RFA procedures were successfully performed without technical problems. During a 30 day period following each RFA procedure, two patients experienced fever $\left(38.2\right.$ and $38.9^{\circ} \mathrm{C}$, respectively) and another patient exhibited post-endoscopic retrograde cholangiopancreatography pancreatitis. The 30- and 90-day mortality rates were 0 and $8.3 \%$, respectively. Mean stricture diameter prior to RFA was $5.3 \mathrm{~mm}$ (standard deviation (SD), $0.9 \mathrm{~mm}$; range, 5-8 $\mathrm{mm}$ ), and the mean diameter following RFA was $12.6 \mathrm{~mm}$ (SD, $3.1 \mathrm{~mm}$; range, $8-15 \mathrm{~mm}$ ). There was a significant increase of $7.3 \mathrm{~mm}$ in the bile duct diameter following RFA in comparison with prior to RFA ( $t=8.6$; $\mathrm{P} \leq 0.001)$. Of the 11 patients with stents inserted following RFA, the median stent patency was 125.0 days [ $95 \%$ confidence interval (CI), 94.7-155.3 days]. Extrapolated median survival following the first RFA was 232 days (95\% CI, 94.3-369.7 days). In
\end{abstract}

Correspondence to: Dr Lin Miao or Dr Guozhong Ji, Medical Center for Digestive Diseases, The Second Affiliated Hospital of Nanjing Medical University, 121 Jiangjiayuan Road, Nanjing, Jiangsu 210011, P.R. China

E-mail:miaolinxh@163.com

E-mail: jgzzl@163.com

Key words: endoscopic retrograde cholangiopancreatography, radiofrequency ablation, malignant biliary strictures, endoscopy, cholangiocarcinoma conclusion, RFA appears to be an efficient and safe treatment strategy for the palliation of unresectable malignant biliary strictures.

\section{Introduction}

Malignant biliary strictures are caused by numerous primary or metastatic disease in intrahepatic, extrahepatic or hilar locations (1). Surgical resection is the best, and potentially curative, therapy available. Regrettably, between 70 and $90 \%$ of patients possess malignant biliary strictures that are unresectable at diagnosis; thus, biliary decompression becomes the primary goal of intervention (2). Compared with surgical intervention, stent insertion offers shorter hospitalization, lower overall cost and lower morbidity (2). Therefore, endoscopic stenting of the biliary tract has become the standard therapeutic technique for patients with a life expectancy of $>3-6$ months $(3,4)$.

Previous studies have demonstrated the superiority of self-expanding metal stents (SEMS) over plastic stents for maintaining biliary drainage (5-7). However, SEMS can become occluded due to epithelial hyperplasia, tumor ingrowth or overgrowth, biofilm deposition and sludge formation (8). Studies have demonstrated that the median SEMS patency is 120 days $(5,9)$; however, once biliary stricture occurs, it may lead to morbidity and mortality. Therefore, long-term patency of SEMS remains an unresolved issue.

A number of methods, including covered nitinol SEMS and endoscopic photodynamic therapy (PDT), have been proposed for increasing the duration of stent patency in malignant biliary strictures (10-12). In 2010, Gao et al (13) reviewed 20 relevant studies and concluded that PDT offered considerable benefit for the survival and quality of life of patients with unresectable cholangiocarcinoma. However, the most common adverse events of PDT are cholangitis $(27.5 \%)$ and phototoxicity $(10.2 \%)(13)$. In addition, the management of patients treated with PDT remains expensive and time consuming.

Radiofrequency ablation (RFA), which can be performed either percutaneously or intraoperatively, has been used to achieve localized tumor necrosis in solid neoplasms for a number of years $(14,15)$. The technique delivers a high quantity of thermal energy to the target tissue, with a curative or palliative intent. Preliminary animal studies $(16,17)$ and human clinical studies $(18,19)$ have investigated a 
promising endoscopic therapy for patients with malignant biliary strictures. The aim of the present study was to evaluate the feasibility and safety of endoscopic RFA for the treatment of malignant biliary strictures.

\section{Materials and methods}

Ethics statement. The present study was approved by the Medical Center for Digestive Diseases, the Second Affiliated Hospital of Nanjing Medical University (Nanjing, China). In addition, institutional review board approval was obtained for this retrospective study. Each patient was fully informed of the details and complications of the procedure, and written informed consent was obtained.

Patients. A total of 12 patients (6 male and 6 female; median age, 68 years; age range, $46-82$ years) with unresectable malignant biliary strictures were referred to the Medical Center for Digestive Diseases and underwent endoscopic RFA between December 2011 and October 2013. The majority (10/12) of the patients were referred to the Center due to jaundice, whereas the remaining patients complained of upper abdominal discomfort. Prior to the RFA procedure, all biliary strictures were confirmed by magnetic resonance cholangiopancreatography, computer tomography or endoscopic retrograde cholangiopancreatography (ERCP).

The following variables were measured: Patient demographics, procedure-related complications, duration of hospital stay, adverse events within 30 days post-intervention, stent patency following the last electively performed RFA procedure in each patient, and 30- and 90-day mortality rates. Stent patency and patient survival time were assessed using Kaplan-Meier statistical analysis.

ERCP procedure. ERCP was performed using a duodenoscope (TJF 260 V; Olympus Corporation, Tokyo, Japan) and a Habib $^{\text {TM }}$ EndoHBP catheter (EMcision, London, UK). The catheter had an $8 \mathrm{~F}$ bipolar probe and two ring electrodes ( $8 \mathrm{~mm}$ apart), with the distal electrode $5 \mathrm{~mm}$ from the leading edge, providing local coagulative necrosis over a length of $2.5 \mathrm{~cm}$ (Fig. 1). The catheter is compatible with standard side-viewing endoscopes (3.2 mm working channel), and can be passed over 0.035 inch guidewires. Ablation was performed using an RFA generator (1500 RF generator; RITA Medical Systems, Inc., Fremont, CA, USA), which delivered electrical energy at $400 \mathrm{kHz}$ and was set at 7-10 $\mathrm{W}$ for 90-120 sec.

Following cannulation of the common bile duct, a cholangiography was performed to assess the length, diameter and location of the biliary stricture. An RF catheter was placed through the biliary stricture under fluoroscopic guidance. Following RFA, a plastic stent (Flextent; Changzhou New District Garson Medical Stent Apparatus Co., Ltd., Changzhou, China) or SEMS (Wallstent; Boston Scientific, Ltd., Marlborough, MA, USA) was applied. Subsequently, a cholangiogram was obtained to confirm the correct positioning of the endoscopic stent and the patency of the biliary tract (Fig. 2).

RFA energy can be delivered repetitively at different tumor sites within one procedure, according to the stricture size. It is recommended that the probe be kept stable for 1 min following

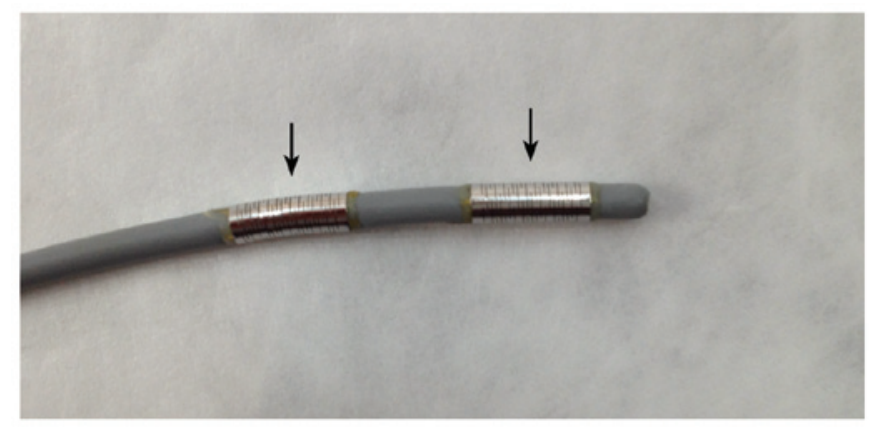

Figure 1. Habib ${ }^{\text {TM }}$ EndoHPB catheter. Endoscopic retrograde cholangiopancreatography was performed under standard operating conditions with a duodenoscope and a Habib ${ }^{\mathrm{TM}}$ EndoHBP catheter with two $8 \mathrm{~mm}$ long electrodes (arrows)

the delivery of RFA energy in order to avoid the adhesion of tissue to the electrodes (18). Each patient was followed-up regularly following the procedure, and no patients were lost to follow-up. The mean follow-up period was 10.8 months (range, 6-19 months).

Statistical analysis. SPSS version 17.0 (SPSS, Inc., Chicago, IL, USA) was used to perform data analysis. Continuous variables were compared using t-test. Stent patency and patient survival time were assessed using Kaplan-Meier statistics.

\section{Results}

Patient demographics. A total of 12 patients underwent 20 RFA procedures for the treatment of malignant biliary strictures. Among them, nine patients had unresectable hilar cholangiocarcinoma (Bismuth classification type $\mathrm{I}, \mathrm{n}=5$; type IIIa, n=1; and type IV, n=3) (20), one patient had primary liver cancer with hepatectomy, one patient had gastric cancer with gastrectomy and one patient had congenital choledochal cysts with high grade intraepithelial neoplasia. Patient demographics are shown in Table I.

RFA procedures. Endoscopic RFA was performed on the patient diagnosed with congenital choledochal cysts with high grade intraepithelial neoplasia. The remaining patients received plastic stents or SEMSs following endoscopic RFA. A total of seven patients underwent plastic stent insertion prior to endoscopic RFA, two of whom received SEMSs following endoscopic RFA; the remaining patients underwent plastic stent exchange. In one patient, RFA was performed inside the stent to reestablish patency of the occluded SEMS. Two patients with Bismuth IV hilar cholangiocarcinoma underwent immunological cytotherapy following endoscopic RFA. All 20 RFA procedures were performed without any technical problems. A total of 16 RFAs were performed using ERCP and four were performed using a percutaneous choledochoscope-assisted approach. A total of 14 RFA procedures were performed at $10 \mathrm{~W}$ for $90 \mathrm{sec}$, whereas the remaining six RFA procedures were performed at $7 \mathrm{~W}$ for $120 \mathrm{sec}$.

The majority of patients (10/12 patients) underwent only one RFA session. Repetitive RFA sessions were electively 
Table I. Patient demographics.

\begin{tabular}{lc}
\hline Parameter & Variable \\
\hline Number of patients & 12 \\
Median age (range), years & $68(46-82)$ \\
Gender (male/female) & $6 / 6$ \\
Disease & \\
Cholangiocarcinoma & 9 \\
Bismuth type I & 5 \\
Bismuth type IIIa & 1 \\
Bismuth type IV & 3 \\
Primary liver cancer & 1 \\
Gastric cancer & 1 \\
Congenital choledochal cysts & 1 \\
\hline
\end{tabular}

Table II. Procedure details and biochemical parameters.

\begin{tabular}{lc}
\hline Parameter & Variable \\
\hline Length of stricture, mm & $18 \pm 9.5^{\mathrm{a}}$ \\
Median number of ablations (range) & $1(1-6)$ \\
Preablation diameter, $\mathrm{mm}$ & $5.3 \pm 0.9^{\mathrm{a}}$ \\
Postablation diameter, $\mathrm{mm}$ & $12.6 \pm 3.1^{\mathrm{a}}$ \\
Preablation bilirubin, $\mu \mathrm{mol} / \mathrm{l}$ & $297.5 \pm 210.5^{\mathrm{a}}$ \\
Postablation bilirubin, $\mu \mathrm{mol} / \mathrm{l}$ & $134.3 \pm 86.4^{\mathrm{a}}$ \\
\hline
\end{tabular}

${ }^{a}$ Mean \pm standard deviation.

performed in two patients, one of whom had been diagnosed with primary liver cancer, and the other had been diagnosed with congenital choledochal cysts ( 6 and 4 times, respectively).

Following the RFA procedure, SEMSs were placed in four patients, and plastic stents were placed in seven patients. No stent was placed in the patient with congenital choledochal cysts. The mean hospital stay following the RFA procedure was 8.9 days (range, 2-22 days). No severe complications, such as hemorrhage, bile leak, sepsis, biliary stricture and iatrogentic thermal injury to adjacent structures occurred prior to or following the procedure.

Biochemical parameters. Postoperative white blood cell (WBC) counts were elevated in four patients, two of whom experienced fever (38.2 and $38.9^{\circ} \mathrm{C}$, respectively). Serum amylase levels were elevated in five patients, one of whom was diagnosed with post-ERCP pancreatitis. All of the patients were managed with conventional therapy.

The median length of the strictures treated was $17.5 \mathrm{~mm}$. The mean stricture length treated was $18 \mathrm{~mm}$ (SD, $9.5 \mathrm{~mm}$; range, 8-35 $\mathrm{mm}$ ). The mean stricture diameter prior to RFA was $5.3 \mathrm{~mm}$ (SD, $0.9 \mathrm{~mm}$; range $5-8 \mathrm{~mm}$ ), while the mean diameter following RFA was $12.6 \mathrm{~mm}$ (SD, $3.1 \mathrm{~mm}$; range 8-15 mm). The stricture diameters prior to and following RFA were compared using a paired t-test. There was a significant increase of $7.3 \mathrm{~mm}(\mathrm{t}=8.6, \mathrm{P} \leq 0.001)$ in the bile duct diameter following RFA compared with prior to RFA.
The mean bilirubin expression level prior to RFA was $297.5 \mu \mathrm{mol} / 1$ (SD, $210.5 \mu \mathrm{mol} / 1$; range 74.6-647.3 $\mu \mathrm{mol} / 1$ ), while the mean bilirubin expression level following RFA was $134.3 \mu \mathrm{mol} / 1$ (SD, $86.4 \mu \mathrm{mol} / 1$; range 31.2-225.2 $\mu \mathrm{mol} / \mathrm{l}$ ). There was a significant decrease in the expression level of bilirubin $(163.2 \mu \mathrm{mol} / \mathrm{l})$ following $\mathrm{RFA}(\mathrm{t}=3.3, \mathrm{P}=0.011$; Table II) compared with prior to RFA.

Each patient was followed-up regularly following the procedure (mean, 10.8 months; range, 6-19 months), and no patients were lost to follow-up. At the end of follow-up, three patients were alive, two of which had SEMS patency, and the third with plastic stent patency.

Mortality rates. Marking the first RFA procedure of each patient as day 1 , the 30 - and 90-day mortality were 0 and $8.3 \%$, respectively. One patient succumbed to cachexia on day 40 .

Stent patency. In each patient, stent patency was assessed from the time at which the final elective RFA procedure was performed. All stents were patent on day 30. One patient succumbed to mortality due to cachexia on day 40 with SEMS patency. One patient exhibited plastic stent occlusion on day 40. The second stent occlusion occurred in a patient with a plastic stent on day 95 .

Of the patients treated with SEMS $(n=4)$, the median stent patency was 125 days (95\% confidence interval (CI), 0-252.2 days); two patients succumbed to mortality on days 40 and 125 with patent stents. Of the patients treated with plastic stents $(n=7)$, the median stent patency was 107 days (95\% CI, 101.9-112.1 days). No significant difference was detected between the metal and plastic stents $(\mathrm{P}=0.84)$. Of the 11 patients with stents inserted following RFA, the median stent patency was 125 days (95\% CI, 94.7-155.3 days) and the mean stent patency was 131 days (95\% CI, 97.3-164.7 days) (Fig. 3).

Kaplan-Meier survival curve analysis showed that the extrapolated median survival following the first RFA was 232.0 days (95\% CI, 32.0-432.0 days), and the extrapolated mean survival was 304.7 days (95\% CI, 151.3-458.1 days) (Fig. 4).

\section{Discussion}

RFA, which can be performed percutaneously or intraoperatively, is used to achieve localized tumor necrosis in primary and secondary hepatic tumors $(21,22)$. During RFA, a high quantity of thermal energy is delivered to target tissue, which may prolong the duration of stent patency (23). RFA has demonstrated promising results for treating malignant biliary strictures in previous studies $(18,19)$.

In the present study, 20 RFA procedures were successfully performed in $100 \%$ of the patients, and there were no difficulties introducing other catheters following stent insertion. The present results demonstrated that the median stent patency of the 11 patients with stents inserted following RFA was 125 days and the mean stent patency was 131 days, which is consistent with the results of a study by Loew et al (9). However, the present results showed that the median duration of stent patency in four patients with SEMS was 125 days, and that of the seven patients with plastic stents was 107 days. 
A

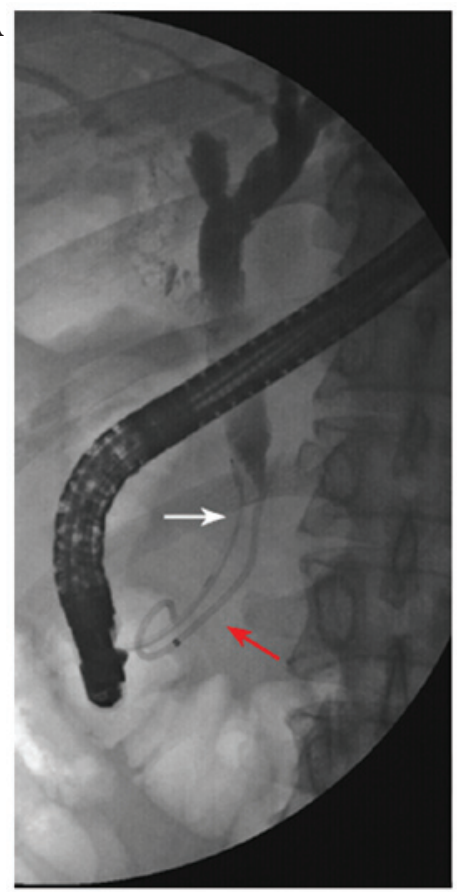

B

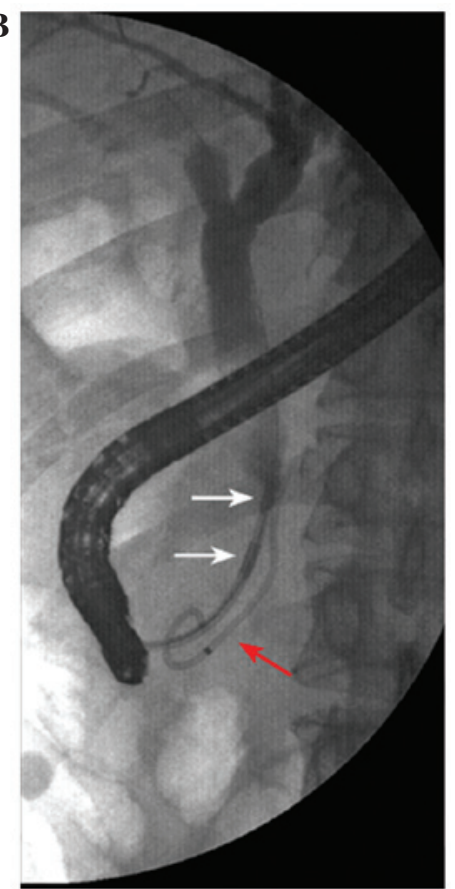

C

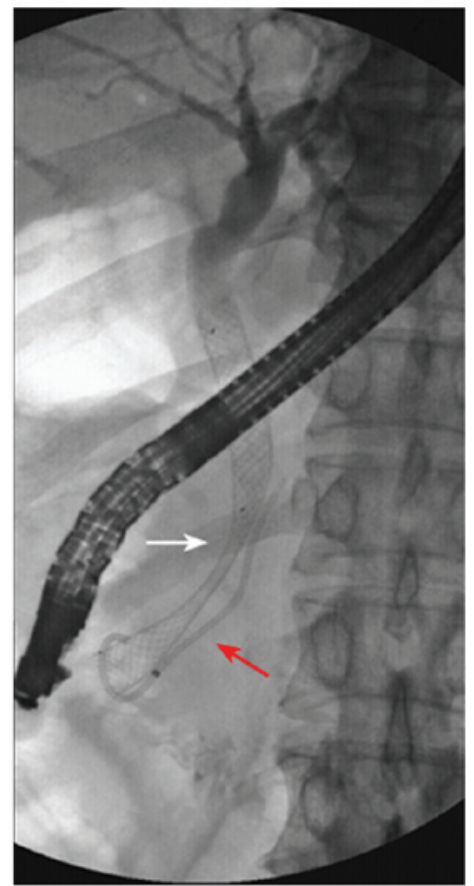

Figure 2. Application of endoscopic radiofrequency ablation. A prophylactic pancreatic stent (red arrow) was inserted prior to the cannulation of the common bile duct. (A) Cholangiogram was obtained to assess the length, diameter and location of the biliary stricture (white arrow). (B) A radiofrequency catheter was placed through the biliary stricture under fluoroscopic guidance (the two electrodes are marked with white arrows). (C) Cholangiogram was obtained to confirm the correct position of the self-expanding metal stents (white arrow) and the patency of biliary tracts.

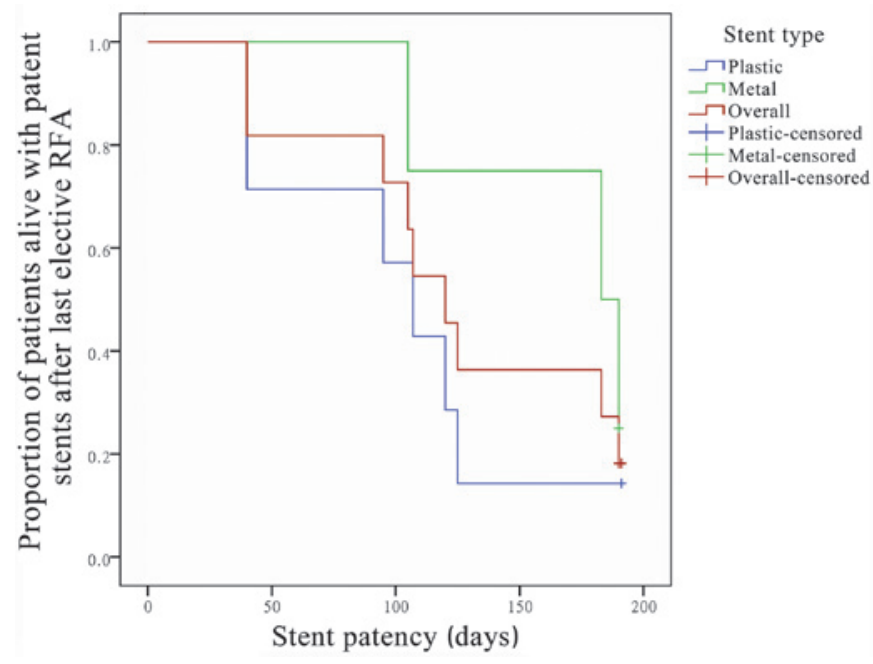

Figure 3. Kaplan-Meier curve of stent patency. Calculation begins on the day of the last electively performed RFA procedure in each patient, and ends on the day of proven stent occlusion, stent migration or patient mortality.

There was no significant difference between the two groups Previous studies have shown that the duration of stent patency of SEMS was longer compared with that of plastic stents (5-7). Therefore, the present results are inconsistent with the findings of previous studies, which may be due to the relatively small study population investigated in the present study and another one patient experienced post-ERCP pancreatitis. Each patient was managed with conventional therapy. Elevated WBC counts were detected in four patients, two of whom had a fever, which could be regarded as a common reaction following the procedure.

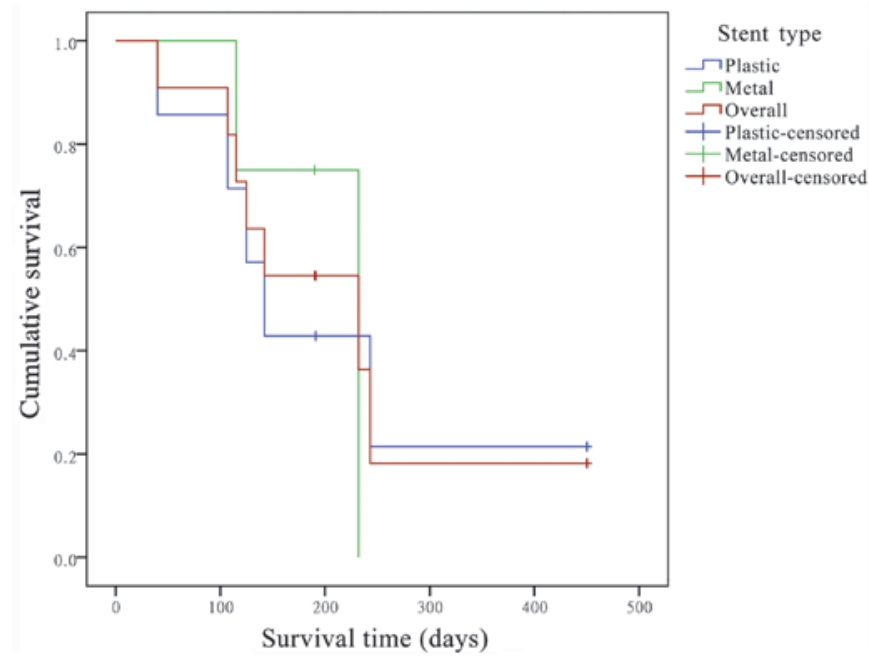

Figure 4. Kaplan-Meier survival curve of patient survival. Calculation begins on the day of the first RFA procedure. Extrapolated median survival is 232 days (95\% confidence interval, 32.0-432.0 days).

These results suggested that RFA treatment of malignant biliary strictures in the present study was safe and effective. However, endoscopic RFA may induce iatrogenic thermal injury to adjacent structures, and the iatrogenic thermal injury may lead to perforation of involved or intact bile ducts, or vessel injury $(21,24)$. Dolak et al (19) have previously described a case of partial liver infarction in a 49 -year-old patient with Bismuth IV hilar cholangiocarcinoma following an RFA procedure. The authors hypothesized that this event was caused by thermal injury to a segmental branch of a liver artery. Finally, the patient was managed conservatively and 
presented with a favorable course. The authors recommended pre-interventional imaging to accurately assess the tumor surroundings, in particular the vascular and biliary structures, particularly for the treatment of proximal strictures.

Tal et al (24) described three cases of hemobilia that occurred within 4-6 weeks of an RFA procedure. Two patients succumbed to hemorrhagic shock, and the surviving patient was managed with immediate SEMS insertion into the bleeding bile duct. The authors hypothesized the hemobilia may be caused by the necrotic effect induced by RFA. Possible preemptive strategies to avoid biliary bleeding complications include pre-interventional assessment with intraductal ultrasound to exclude large blood vessels in the surrounding tissue. Inserting a SEMS immediately after the RFA procedure may be an effective method for the prevention of late bleeding complications.

Notably, in the present study, one patient with congenital choledochal cysts and high grade intraepithelial neoplasia underwent the RFA procedure four times between March 2013 and October 2013. The patient was a 47-year-old male with type IV-A congenital choledochal cysts who underwent cyst excision of the dilated extrahepatic bile duct with Roux-en-Y hepaticojejunostomy prior to the RFA procedure. A T-tube was inserted into the common hepatic duct during the operation, and the RFA procedure was performed using a choledochoscopic approach. The patient attended regular follow-ups, tolerated the procedure well and experienced good palliation of his symptoms (25).

In conclusion, the present study demonstrated that RFA is an efficient and safe treatment strategy for the palliation of unresectable malignant biliary strictures. However, the study was a retrospective analysis with a small population, which are notable limitations. A large-scale, prospective multicenter trial with a long-term follow-up evaluation period is required in order to further quantify the benefits of RFA on stent patency and survival rates.

\section{References}

1. Webb K and Saunders M: Endoscopic management of malignant bile duct strictures. Gastrointest Endosc Clin N Am 23: 313-331, 2013.

2. Moss AC, Morris E, Leyden J and MacMathuna P: Malignant distal biliary obstruction: A systematic review and meta-analysis of endoscopic and surgical bypass results. Cancer Treat Rev 33 213-221, 2007.

3. Shepherd HA, Royle G, Ross AP, Diba A, Arthur M and Colin-Jones D: Endoscopic biliary endoprosthesis in the palliation of malignant obstruction of the distal common bile duct: A randomized trial. Br J Surg 75: 1166-1168, 1988.

4. Andersen JR, Sorensen SM, Kruse A, Rokkjaer M and Matzen P: Randomised trial of endoscopic endoprosthesis versus operative bypass in malignant obstructive jaundice. Gut 30: 1132-1135, 1989.

5. Kaassis M, Boyer J, Dumas R, Ponchon T, Coumaros D, Delcenserie R, Canard JM, Fritsch J, Rey JF and Burtin P: Plastic or metal stents for malignant stricture of the common bile duct? Results of a randomized prospective study. Gastrointest Endosc 57: 178-182, 2003.

6. Soderlund C and Linder S: Covered metal versus plastic stents for malignant common bile duct stenosis: A prospective, randomized, controlled trial. Gastrointest Endosc 63: 986-995, 2006.
7. Hong W, Sun $\mathrm{X}$ and Zhu Q: Endoscopic stenting for malignant hilar biliary obstruction: Should it be metal or plastic and unilateral or bilateral? Eur J Gastroenterol Hepatol 25: 1105-1112, 2013.

8. Donelli G, Guaglianone E, Di Rosa R, Fiocca F and Basoli A: Plastic biliary stent occlusion: factors involved and possible preventive approaches. Clin Med Res 5: 53-60, 2007.

9. Loew BJ, Howell DA, Sanders MK, Desilets DJ, Kortan PP, May GR, Shah RJ, Chen YK, Parsons WG, Hawes RH, et al: Comparative performance of uncoated, self-expanding metal biliary stents of different designs in 2 diameters: Final results of an international multicenter, randomized, controlled trial. Gastrointest Endosc 70: 445-453, 2009.

10. Telford JJ, Carr-Locke DL, Baron TH, Poneros JM, Bounds BC, Kelsey PB, Schapiro RH, Huang CS, Lichtenstein DR, Jacobson $\mathrm{BC}$, et al: A randomized trial comparing uncovered and partially covered self-expandable metal stents in the palliation of distal malignant biliary obstruction. Gastrointest Endosc 72: 907-914, 2010.

11. Kullman E, Frozanpor F, Söderlund C, Linder S, Sandström P, Lindhoff-Larsson A, Toth E, Lindell G, Jonas E, Freedman J, et al: Covered versus uncovered self-expandable nitinol stents in the palliative treatment of malignant distal biliary obstruction: results from a randomized, multicenter study. Gastrointest Endosc 72: 915-923, 2010.

12. Rumalla A, Baron TH, Wang KK, Gores GJ, Stadheim LM and de Groen PC: Endoscopic application of photodynamic therapy for cholangiocarcinoma. Gastrointest Endosc 53: 500-504, 2001.

13. Gao F, Bai Y, Ma SR, Liu F and Li ZS: Systematic review: Photodynamic therapy for unresectable cholangiocarcinoma. J Hepatobiliary Pancreat Sci 17: 125-131, 2010.

14. Bruix J and Sherman M: Management of hepatocellular carcinoma: an update. Hepatology 53: 1020-1022, 2011.

15. Siperstein AE, Berber E, Ballem N and Parikh RT: Survival after radiofrequency ablation of colorectal liver metastases: 10-Year experience. Ann Surg 246: 559-565, 2007.

16. Itoi T, Isayama $\mathrm{H}$, Sofuni A, Itokawa F, Tamura M, Watanabe $\mathrm{Y}$, Moriyasu F, Kahaleh M, Habib N, Nagao T, et al: Evaluation of effects of a novel endoscopically applied radiofrequency ablation biliary catheter using an ex-vivo pig liver. J Hepatobiliary Pancreat Sci 19: 543-547, 2012.

17. Zacharoulis D, Lazoura O, Sioka E, Potamianos S, Tzovaras G, Nicholls J, Koukoulis G and Habib N: Habib EndoHPB: A novel endobiliary radiofrequency ablation device. An experimental study. J Invest Surg 26: 6-10, 2013.

18. Steel AW, Postgate AJ, Khorsandi S, Nicholls J, Jiao L, Vlavianos P, Habib N and Westaby D: Endoscopically applied radiofrequency ablation appears to be safe in the treatment of malignant biliary obstruction. Gastrointest Endosc 73: 149-153, 2011 .

19. Dolak W, Schreiber F, Schwaighofer H, Gschwantler M, Plieschnegger W, Ziachehabi A, Mayer A, Kramer L, Kopecky A, Schrutka-Kölbl C, et al: Endoscopic radiofrequency ablation for malignant biliary obstruction: A nationwide retrospective study of 84 consecutive applications. Surg Endosc 28: 854-860, 2014.

20. Bismuth H, Nakache R and Diamond T: Management strategies in resection for hilar cholangiocarcinoma. Ann Surg 215: 31-38, 1992.

21. Cho YK, Kim JK, Kim MY, Rhim H and Han JK: Systemic review of randomized trials for hepatocellular carcinoma treated with percutaneous ablation therapies. Hepatology 49: 453-459, 2009.

22. Izumi N: Recent advances of radiofrequency ablation for early hepatocellular carcinoma. J Gastroenterol Hepatol 26 (Suppl 1): S115-S122, 2011

23. Wadsworth CA, Westaby D and Khan SA: Endoscopic radiofrequency ablation for cholangiocarcinoma. Curr Opin Gastroenterol 29: 305-311, 2013.

24. Tal AO, Vermehren J, Friedrich-Rust M, Bojunga J, Sarrazin C, Zeuzem S, Trojan J and Albert JG: Intraductal endoscopic radiofrequency ablation for the treatment of hilar non-resectable malignant bile duct obstruction. World J Gastrointest Endosc 6: 13-19, 2014.

25. Wang F, Li Q, Ge X, Yu H, Nie J and Miao L: Choledochoscopic radiofrequency ablation for congenital choledochal cysts. Endoscopy 46 (Suppl 1): E373-E374, 2014. 